Proceedings of the 32nd Annual Meeting of the Brazilian Embryo Technology Society (SBTE); Florianopólis, SC, Brazil, August 16th to 18th, 2018.

\title{
Contributions from the ovarian follicular environment to oocyte function
}

\author{
Maite del Collado, Gabriella Mamede Andrade, Flávio Vieira Meirelles, \\ Juliano Coelho da Silveira, Felipe Perecin ${ }^{1}$
}

${ }^{1}$ Faculty of Animal Sciences and Food Engineering, Department of Veterinary Medicine, University of São Paulo, Pirassununga, SP, Brazil.

\begin{abstract}
The magnitude of oocyte's role for embryo development is categorical. This unique cell contains the machineries and cellular components necessary to remodel male and female chromatin, to sustain early development and to, ultimately, generate a complete and complex individual. However, to gain these competences before fertilization, the oocyte undergoes several morphological, cellular and molecular changes during its lifetime enclosed in the ovarian follicle. This review will briefly revisit how the oocyte orchestrate the follicular cells, and how molecules transit to the oocyte from the innermost (cumulus) and outermost (antrum and granulosa cells) layers surrounding the follicleenclosed oocyte. Finally, we will discuss the interferences of in vitro culture conditions in the communication of the oocyte with its surrounding cells and the potential strategies to modulate these communication systems to increase oocyte competence.
\end{abstract}

Keywords: cell-to-cell communication, cumulus-oocyte interactions, extracellular vesicles.

\section{Introduction}

In females, before birth, cohorts of primordial germ cells migrate to the genital ridge and establish contact with pre-granulosa. Meiosis is triggered and the primordial follicles are formed by primary oocytes surrounded by small squamous granulosa cells (Fortune, 1994; Eppig, 2001; Edson et al., 2009). The initial steps of follicular development are gonadotropin-independent and is essentially driven by locally secreted factors (Eppig, 2001). During the growth phase these granulosa cells change from squamous to cuboidal originating the primary follicle (Fortune, 1994; Eppig, 2001; Edson et al., 2009). As the oocyte grows, the zona pellucida, composed by glycoproteins, is formed constituting a physical barrier separating the oocyte and the granulosa cells (Clarke, 2018). As granulosa cells proliferate and generate multiple layers, the follicle is denominated secondary follicle (Fortune, 1994; Eppig, 2001; Edson et al., 2009). When the antrum appears within the follicle, granulosa cells are divided into cumulus cells and granulosa or mural cells (Fortune, 1994; Eppig, 2001; Edson et al., 2009). From this moment, the oocyte slows or stops its growth, even though the follicle continues to grow, under the influence of mainly follicle stimulating hormone (FSH) up to the pre-ovulatory stage (Fair et al., 1995; Eppig, 2001; Clarke, 2018). A peak of luteinizing hormone (LH) leads to mature cumulus-oocyte complex (COC) ovulation (Fortune, 1994).

During the oocyte and follicle development, intense communication between the oocyte and the components within the follicular environment occurs to ensure the acquisition of oocyte developmental capacity. Until the follicle reaches the antral or tertiary stage, the folliculogenesis is independent of gonadotrophins and morphological and functional changes are controlled by paracrine signals (Gilchrist et al., 2008). The oocyte commands these processes, in part, by oocyte-secreted factors (OSF). The molecules from the transforming growth factor-beta (TGF-B) superfamily are some of the most important OSF and, among them, Growth/differentiation factor 9 (GDF9) and Bone morphogenetic protein 15 (BMP15) have critical role during oocyte and follicle growth (Gilchrist et al., 2008). GDF9 and BMP15 expression are detectable in oocytes as soon as the primordial or primary follicle stages, depending on the species (Eppig, 2001). Oocyte releases GDF9 that acts in granulosa/cumulus cells through $\mathrm{SMAD} 2 / 3$ signaling (Kaivo-Oja et al., 2003; Kaivo-Oja et al., 2005), whereas BMP15 signals through SMAD1/5/8 (Moore et al., 2003; Pulkki et al., 2011). Both molecules can form homodimers and heterodimers and their proportions and functions vary in different species.

The importance of OSF for oocyte development was clearly demonstrated in mice once the knockout of these factors lead to sterile animals or animal with reduced fertility (Dong et al., 1996; Eppig, 2001; Yan et al., 2001). A plethora of roles for GDF9 and BMP15 during oocyte maturation and folliculogenesis has been described. To exemplify, these OSF participate in the regulation of the oocyte growth factor KitL, increasing its expression in cumulus cells during oocyte growth and decreasing its expression when the oocyte is fully developed (Eppig, 2001; Gilchrist et al., 2008); also, stimulate cell proliferation and drive the differentiation of granulosa and cumulus cells during folliculogenesis. These evidences indicate that the oocyte modulate the surrounding cells in order to gain developmental competence.

However, the idea that the oocyte is the singular source of molecules that are accumulated during oocyte acquisition of competence has been contrasted by in vitro maturation studies, as reviewed by Robert and Gilbert (2018). In cattle, the oocyte reaches its full-size when the follicle is around $3 \mathrm{~mm}$ in diameter (Lodde et al., 2008). These follicles contain 
oocytes in germinal vesicle $(\mathrm{GV})$, that can be classified as GV1, GV2 or GV3 according to their chromatin condensation stage, which is correlated to the transcriptional activity (Luciano and Sirard, 2018). In GV1, the oocyte chromatin became partially condensed followed by a wide transcription decrease, while in GV3, the chromatin is totally condensed in a state of complete transcriptional inactivation (Luciano et al., 2011; Lodde et al., 2013). Oocytes derived from follicles measuring 3 to $6 \mathrm{~mm}$ in diameter are usually used for in vitro production of bovine embryos, with development up to the blastocysts stage reaching 30 to $40 \%$. When oocytes from larger follicles (around $8 \mathrm{~mm}$ ) are used, blastocyst rate increase to $60 \%$ is observed (Rizos et al., 2002b).
Even though oocytes either from 3-6 $\mathrm{mm}$ or $8 \mathrm{~mm}$ follicles are full-sized and transcriptionally inactive, the development competence is higher when they are kept longer within the follicular environment (Lonergan et al., 1994), suggesting that cell-to-cell communications during the final stage of follicle maturation is decisive to increase the oocyte competence. Thus, follicular components and cumulus cells supply factors or molecules needed by the oocyte to reach its full competence. Here we will discuss the current knowledge about the communication within the ovarian follicle (Figure 1), focusing on the movement of molecules from outward follicle components to the cumulus-oocyte complexes and from the cumulus cells to the oocyte.
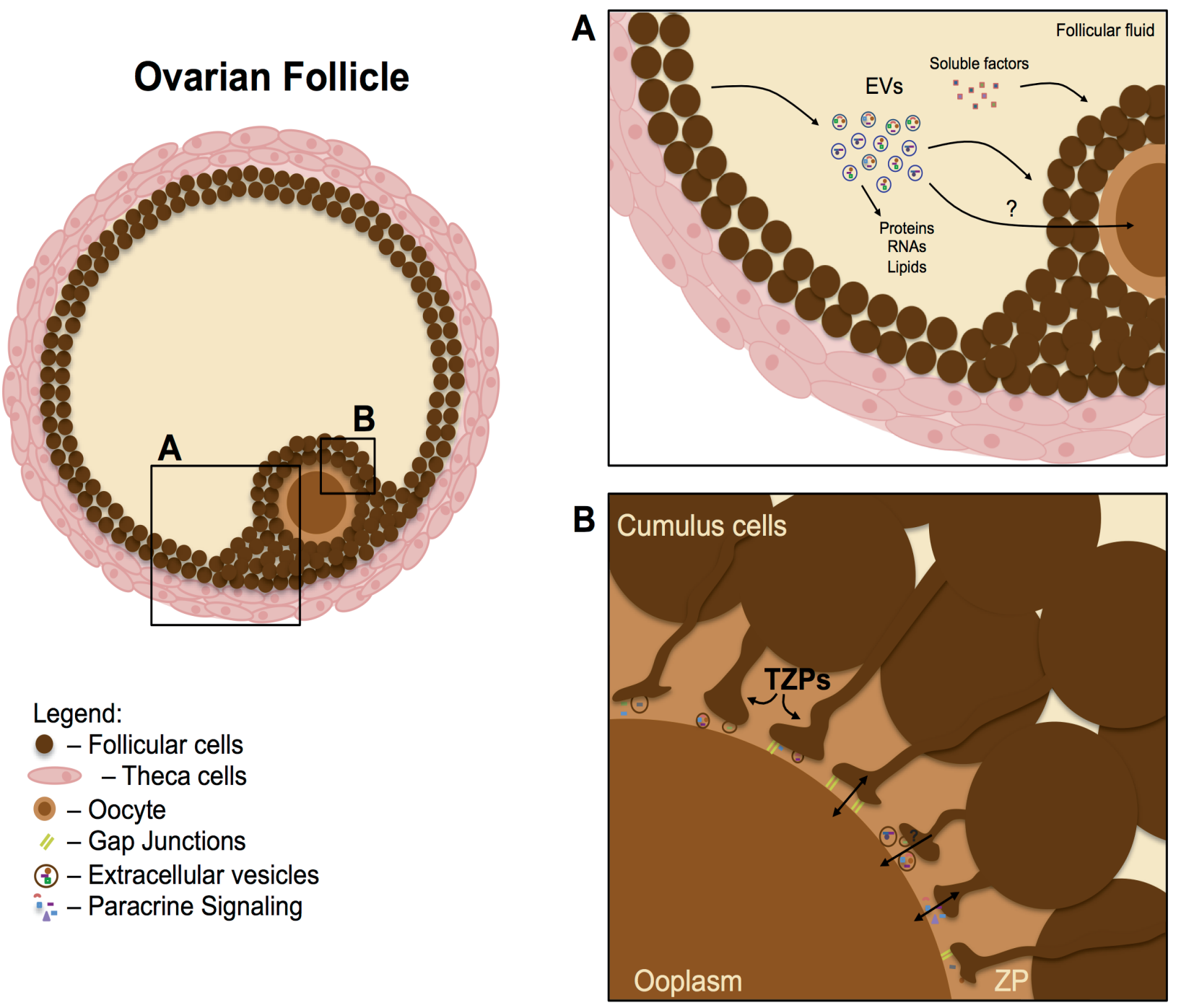

Figure 1. Communication within the ovarian follicle. Schematic representation of the intercellular communication within the antral ovarian follicle. A. Cellular communication in the follicular environment includes the secretion of paracrine factors (soluble factors) and a mechanism mediated by extracellular vesicles (EVs). These vesicles are present in follicular fluid and can carry and transfer macromolecules as mRNAs, microRNAs and proteins between granulosa cells, including the mural granulosa and cumulus. However, the eventually delivery to the oocyte of EVs' contents transiting in the follicular fluid is yet to be experimentally observed $\mathbf{B}$. The communication between the cumulus cells and the oocyte occurs by paracrine signaling. After the formation of the zona pellucida (ZP) this communication is also possible via transzonal projections (TZPs). At the bulk edges of TZPs gap junctions are established between cumulus cells' membrane and the oolema. Structures like EVs have already been identified in the TZPs bulk edges, in the clefts formed between TZPs and the oolema. 


\section{Relations between the follicular cells and the oocytes}

Each follicular cell type within the follicular microenvironment play a role in supporting the oocyte growth, maturation and acquisition of competence. Indeed, several studies have associated follicular cells characteristics, such as gene expression and signaling pathways activity, with oocyte competence. For example, the expression of the gene estrogen receptor 1 (ESR1) in granulosa cells and of the gene versican $(V C A N)$ in thecal cells was positively associated with oocyte competence (Matoba et al., 2014). In cumulus cells, genes such as hyaluronan synthase 2 (HAS2), Gremlim 1 (GREM1) (Cillo et al., 2007), regulator of G-protein signaling 2 (RGS2) (Feuerstein et al., 2012) and tumor necrosis factor- alpha inducible gene 6 (TNFAIP6a) (Matoba et al., 2014) were positively associated with oocyte competence while the genes such as inducible nitric oxide synthase (iNOS) and heme oxygenase 1 (HO-1) were negatively associated with competence (Bergandi et al., 2014).

Studies that investigated gene expression in follicular cells and the ability of the oocyte to support development commonly identify associations or indirect effects of the follicular cells on the oocytes, rather than direct transfer of molecules among then. In spite of this, the direct transfer of molecules from the follicular cells to the oocytes play an important role for oocytes' competence acquisition. The cumulus and corona cells, in close contact with the oocytes, provide small molecules to the oocytes through TZPs (and ultimately by gap junctions; (Sugiura and Eppig, 2005; Conti et al., 2012). However, communication mechanisms allowing the exchange of large molecules, such as mRNAs and fatty acids (Macaulay et al., 2014; del Collado et al., 2017b), have only recent being described. Large molecules' traffic between outer layers (i.e. mural granulosa) and inner layer (i.e. cumulusoocyte complexes) of the ovarian follicle were recently described with the identification of extracellular vesicles (EVs) transiting in the follicular fluid (da Silveira et al., 2012; Hung et al., 2015). Interestingly, the traffic of large molecules from cumulus to the oocytes has also been recently described through TZPs and ultimately by the transport mediated by EVs released into the cleft between the bulk end of the TZP and the oolema (Macaulay et al., 2014; Macaulay et al., 2016).

\section{From the outer layers to the oocyte}

\section{Extracellular vesicles}

Extracellular vesicles are cell-secreted vesicles that can carry biomolecules such as proteins, mRNAs, miRNAs, metabolites and lipids (Choi et al., 2013; Raposo and Stoorvogel, 2013). Extracellular vesicles are present in different body fluids including follicular fluid of diverse species such as equine, bovine and human (da Silveira et al., 2012; Sang et al., 2013; Sohel et al., 2013; Santonocito et al., 2014; Navakanitworakul et al., 2016). These vesicles can be internalized by granulosa cells in vitro and in vivo (da Silveira et al.,
2012), and by cumulus cells in vitro (Hung et al., 2015; da Silveira et al., 2017), suggesting their importance in intrafollicular communication. Additionally, extracellular vesicles are capable to facilitate the transfer mechanism of different macromolecules (Di Pietro, 2016) not just between somatic cells but also between cumulus cells and the oocyte (Macaulay et al., 2014; Macaulay et al., 2016), as discussed ahead. As the follicle develops extracellular vesicles quantity and content in the follicular fluid vary (Navakanitworakul et al., 2016) and have different effect on cumulus expansion and oocyte gene expression (Hung et al., 2015).

Recently, the role of extracellular vesicles was evaluated during cumulus-oocyte-complex in vitro maturation. Based on two independent studies using bovine as model the functional role of extracellular vesicles appears to be associated with EVs isolated from small follicles compared to large follicles. In the first study treatment of COCs with EVs from small follicles (3-5 mm) was capable to induce cumulus expansion and genes related to its function (Hung et al., 2015). In a second study, extracellular vesicles isolated from 3-6 $\mathrm{mm}$ follicles were supplemented during $\mathrm{COC}$ in vitro maturation and early embryo development and were capable to induce changes in gene expression as well as global methylation and hydroxymethylation levels (da Silveira et al., 2017). Among the genes influenced by extracellular vesicles treatment were DNMT3A (DNA methyltransferase 3 alpha), ACSL6 ((Acyl-CoA Synthetase Long Chain Family Member 6), CDH1 (Cadherin-1), REST (RE1-Silencing Transcription factor) and FADS2 (Fatty Acid Desaturase 2), which were increased in blastocysts following small EVs supplementation, during IVM and IVC, in comparison control treated COCs (da Silveira et al., 2017). In addition to that was observed an increase in global methylation and hydroxymethylation upon small EVs supplementation during IVM and IVC in comparison with control treated COCs (da Silveira et al., 2017). Additionally, da Silveira et al., (2017) observed the presence of PKH67 labelled EVs within TZPs suggesting the transfer of follicular fluid EVs to the oocyte; however, it still need to be confirmed (da Silveira et al., 2017). These results indicate that the EVs present in the follicular fluid exert functions in cumulus-oocyte complexes probably by the direct transfer of EV cargo to COCs. The specific component of the EVs driving these effect is still unknown. The most well studied EV content, candidate to directly act into the COCs, are the microRNAs, which have been extensively studied in the follicular microenvironment in association with the oocyte competence.

\section{MiRNAs}

MicroRNAs are small non-coding RNAs regulating gene expression that are present in cells or in follicular fluid and can be associated or not with EVs. MiRNAs can participate in the communication process between follicular cells and the oocyte (Assou et al., 2013); thus, presenting different levels during follicular development (McBride et al., 2012) as well as different 
predicted pathways involved in important cellular processes. For example, miR-130b is involved in increasing granulosa and cumulus cells proliferation and in oocyte maturation (Sinha et al., 2017), probably by targeting SMAD5 and MSK1 (Mitogen- and StressActivated Protein Kinase 1) genes.

In order to investigate the potential roles of

EVs from follicular fluid on the competence of bovine oocytes, our group conducted a series of experiments. We demonstrated the presence of different miRNAs cargos in EVs according to its origin - mural granulosa and COCs (da Silveira et al., 2015; Andrade et al., 2017a). Moreover, we demonstrated that the miRNAs transiting in EVs in the follicular fluid modulate signaling pathways, such as the PI3K-Akt pathway. Additionally, we show that higher or lower activity of the PI3K-Akt signaling pathway into follicular cells correlate with higher or lower developmental competence of the oocytes (Andrade et al., 2017b). Although a direct transfer of molecules from the follicular fluid-EVs to the oocyte has never been show, indirect influence of EVs present in the follicular fluid on oocyte competence was demonstrated using these and other approaches (da Silveira et al., 2017).

\section{The inner layer: from cumulus cells to the oocyte}

Denuded oocytes are not able to reach full competence to support development of an embryo, whereas denuded oocytes co-cultured with cumulus cells have result in increased blastocysts development rates (Fukui and Sakuma, 1980; Zhang et al., 1995; Luciano et al., 2005). This demonstrates the importance of cumulus cells for the oocyte to acquire competence to support embryo development. The COCs are dynamic structures, and the communication among these cell types is intense. The unique architecture of the $\mathrm{COC}$, in which the germ and soma cells are physically separated by a barrier, the zona pellucida, permits the communication mediated by paracrine signals as briefly discussed previously. However, the zona pellucida interposed between the oocyte and cumulus cell do not complete separate the germ and soma compartments, as transzonal projection (TZPs) extends from cumulus cell towards the oocyte. The TZPs allow the traffic of molecules from the cumulus cell to the oocyte by gap junctions or by extracellular vesicles (Sutton et al., 2003b; Macaulay et al., 2014).

The transzonal projections (TZPS) and the traffic of small and large molecules to the oocyte

Besides paracrine signal, cumulus cells and oocytes crosstalk can occur by cumulus cells cytoplasmic projections through zona pellucida establishing a "bridge" connecting the cumulus cells and oocyte oolema, denominated transzonal projections (TZPs) (de Loos et al., 1989; de Loos et al., 1991). In primordial follicles, oocyte and granulosa cells are in direct contact, however, during oocyte growth, the zona pellucida is formed and granulosa cells and oocyte become physically separated. The traffic of molecules between them will be dependent on the TZPs (reviewed by Clarke, 2017). In bovine, it was estimated that TZPs are functional until 9 hours of IVM; after 9 hours of IVM they begin to disrupt and after 18 hours of IVM there are no more active TZPs (Macaulay et al., 2014; del Collado et al., 2017b). The TZPs are composed by cytoplasmic filaments and two types of them have been characterized: the tubulin-TZPs and actin-TZPs (Li and Albertini, 2013). Li and Albertini (2013) proposed two different functions depending on their structure: tubulinTZPs are involved in cell adhesion function, while actin-TZPs, most abundant in COCs, are involved in cell communication. There are evidences of how the TZPs are formed and to what kind of regulation they are subjected. As reviewed by (Clarke, 2018), there are two possible synthesis models: "stretching" and "pushing" models. The first proposes that, when zona pellucida appears, the granulosa cell bodies are stretched away from the oocyte and remaining attached to the original contact point; this model implicates that newborn granulosa cells are not able to synthesize TZPs. According to the "pushing" model, TZPs are generated by granulosa cells that grows toward the oocyte, and de novo TZPs synthesis could occur in proliferating granulosa cells. Although it was thought that only corona radiate cells could connect with the oolema by TZPs, recent studies have demonstrated that more distal layers also have these structures (Jaffe and Egbert, 2017; El-Hayek et al., 2018). In bovines, it was estimated that around 3 thousand TZPs are present per oocyte (Macaulay et al., 2016) and it was observed that mice cumulus cells can synthetized more than one TZP per cell (El-Hayek et al., 2018), pointing an important communication route within the COC.

Molecules such as FSH and GDF9 have been shown to regulate the appearance of these projections. The study performed in mice showed that, in the absence of FSH, an unusual high number of TZPs appear in the oocyte surface, while FSH treatment induces TZPs retraction along with the acquisition of meiotic competence (Combelles et al., 2004). The lack of GDF9 in mice oocytes lead to morphologically abnormal TZPs (Dong et al., 1996; Carabatsos et al., 1998). Moreover, recently, an important work described how GDF9 could play an important role in TZP synthesis regulation via SMAD signaling and Daam1, Fscn 1 and Myol0 proteins and possibly by another OSF, contributing to the regulation of this mechanism in mice (El-Hayek et al., 2018). Although the description of TZPs occurred decades ago, we still do not fully understand what kind and extend of communication these projections permit between the oocyte and surrounding cells. At the end of each TZP, communications occur by gap-junctional traffic or, as recently proposed, mediated by extracellular vesicles (Macaulay et al., 2014).

\section{Gap junctions}

The gap junctions are transmembrane protein structures composed by six connexins. In COCs there are two kinds of gap junctions composed by two 
different types of connexins: the ones linking granulosa/cumulus cells and the ones between cumulus cells and the oocyte (at the bulk end of TZPs). Although this varies depending on the species, it seems that the most common pattern is that connexins 43 are more present in gap junctions between granulosa/cumulus cells, and the connexins 37 in gap junctions linking cumulus cells and the oocyte (Nuttinck et al., 2000; Chang et al., 2016; Russell et al., 2016). Several studies in mice have demonstrated that both connexins are required to normal folliculogenesis and oogenesis (Gershon et al., 2008; Chang et al., 2016). The connexins 43 are regulated by gonadotrophins and steroid hormones, and was recently demonstrated that they are negatively regulated by BMP15 (Petrocelli and Lye, 1993; Granot and Dekel, 2002; Chang et al., 2014; Chang et al., 2016). Studies demonstrated that estradiol and FSH increase, while progesterone and LH decrease connexins 43 levels in many species such as human (Petrocelli and Lye, 1993; Granot and Dekel, 2002). These communications are active from very early folliculogenesis and decrease gradually during growth of mid-antral follicles (2-6 $\mathrm{mm})$ depending on the oocyte GV stage (Lodde et al., 2007). During IVM in bovine, it was described that the number of gap junctions drop at 6-8 hours of culture, with the possibility of extending these communications using molecules that maintain the meiotic arrest in oocytes (Lodde et al., 2013). Gap junction channels transport small molecules $(<1 \mathrm{kDa})$ such as ions, amino acids and metabolites important to oocyte development (Thomas et al., 2004a).

One of most important role of the gap junctions is the maintenance of meiotic arrest in oocyte. In mammals, oocytes are arrest in GV at diplotene stage of Profase I of meiose until preovulatory LH surge. It is well stablished that high level of cyclic adenosine monophosphate (cAMP) within oocyte maintain meiotic arrest, whereas a decreased of cAMP by phosphodiesterase (PDE3A) after LH peak leads to a meiotic resumption (Sirard et al., 1998). Before the surge of LH, PDE3A activity in oocyte is inhibited by cGMP originated from cumulus cells via gap junctions inhibiting meiotic resumption (Norris et al., 2009; Vaccari et al., 2009).

On the other hand, gap junctional communication allows a control of oocyte microenvironment by the traffic of molecules. The oocyte manages the intracellular $\mathrm{pH}$ against acidosis by gap junctions transport of $\mathrm{pH}$ regulators from cumulus cells until the oocyte is able to regulate $\mathrm{pH}$ by itself (FitzHarris et al., 2007). In addition, the oocyte is metabolically restrictive during foliculogenesis, since it contains immature mitochondria not able to perform glycolysis (Sutton-McDowall et al., 2010). Therefore, cumulus cells provide oocyte with metabolites such as pyruvate, that will be metabolized within the oocytes mitochondria during tricarboxylic acid cycle followed by oxidative phosphorylation to generate ATP (Biggers et al., 1967; Sutton-McDowall et al., 2010). Moreover, cysteine and $\mathrm{NAD}(\mathrm{P}) \mathrm{H}$ traffic from cumulus cells to the oocyte via gap junction are involved in GSH (glutathione) synthesis, the most common antioxidant in the oocyte (Sutton et al., 2003a). Finally, the oocytes secrete paracrine factors to promote cumulus cell uptake via gap junctions of amino acids, such as alanine, histidine and leucine, that oocytes themselves transport poorly (Eppig et al., 2005).

\section{Extracellular vesicles}

There are increasing evidences that large molecules such as mRNA, miRNA and proteins could be transported from cumulus cells to the oocyte. Studies conducted by Claude Robert's group (Macaulay et al., 2014; Macaulay et al., 2016) demonstrated the RNA traffic from cumulus cells to the oocyte via TZPs. These studies described several important transcripts that cumulus cells provide to the oocyte at final stage of oocyte maturation, showing how these transcripts could traffic from the cumulus to the oocyte. Moreover, they showed the occurrence of extracellular vesicles (EVs) within a structure that resembles a synapse at the end of TZPs, which suggest an involvement of these vesicles mediating the transport. Recently, our group showed evidences of the transport of Fatty Acid Binding Protein 3 (FABP3) protein from cumulus cells to the oocyte via TZPs and an apparent increase of this traffic during the first 9 hours of IVM in bovines (del Collado et al., 2017a). Additionally, we have demonstrated the increase in lipids similar to the increase and accumulation of FABP3 protein, suggesting that this protein is involved in carrying lipids to the oocyte. In order to demonstrate the mechanism, we impaired actin filament polymerization thus blocking TZPs formation as well as FABP3 movement from cumulus to oocytes. Such strategy resulted in lower amounts of lipids accumulated within the oocyte. Based on these findings we are currently investigating the relationship between FABP3 and extracellular vesicles within the cumulusoocyte-complex. In an attempt to demonstrate the possible transfer of extracellular vesicles from outside of cumulus cells to the oocyte we labeled EVs with PKH67 (membrane lipid dye) and verify the presence of labeled EVs within the zona pellucida, suggesting that these vesicles could use cumulus cells as bridges to achieve the ooplasm (da Silveira et al., 2017).

\section{Disturbances and modulation of the communication within the ovarian follicle}

Interactions inside the follicle microenvironment are coordinated and can lead to decreased oocyte competence if disturbed, or can potentially lead to increased reproductive success if adequately modulated. Understanding how follicular cells and the follicular fluid contents influence the oocyte competence acquisition is fundamental to develop strategies to protect the oocyte from deleterious conditions and to create protocols to improve assisted reproductive technologies. Since a fine coordinated crosstalk within $\mathrm{COC}$ is critic to oocyte competence, any exogenous particle or condition that modify cumulus cells or oocyte cellular or molecular 
characteristics could lead to an erroneous communication pattern, affecting oocyte competence. The most studied altered environment to which the oocytes are exposed is the in vitro culture condition. When immature oocytes undergo IVM several modifications appear (metabolic disturbances, epigenetic disturbances, and others) leading to a lower blastocyst rate, when compared to in vitro production (IVP) of in vivo maturated oocyte (Rizos et al., 2002b). This suggest that disturbances during oocyte maturation, corresponding to the final step of communication between the oocyte and the follicular cell, greatly impact the outcome oocyte competence acquisition.

In vitro maturation alters transcript profiles in cumulus cells and oocytes in several species (Jones et al., 2008; Kues et al., 2008; Katz-Jaffe et al., 2009; Heinzmann et al., 2011; Yuan et al., 2011; Jiang et al., 2014). Since we already know the existence of RNA traffic from cumulus to the oocyte (Macaulay et al., 2014; Macaulay et al., 2016), this traffic and, consequently, the oocyte quality, could be affected by IVM. However, evidences of differential RNA traffic within the $\mathrm{COC}$ under in vivo and in vitro conditions are yet to be demonstrated.

The excessive cytoplasmic lipid droplet accumulation that occur during the in vitro culture of gametes and embryos is extensively studied, and detrimental effects on competence are largely known (Rizos et al., 2002a; Seidel, 2006). We currently know that lipid accumulation occurs during IVM in both oocyte and cumulus cells and that it does not occur during in vivo maturation (del Collado et al., 2016; del Collado et al., 2017a; del Collado et al., 2017b). Notably, we identified that functional modifications including lipid accumulation in in vitro-matured oocytes were not associated with coordinate transcriptional changes; rather, we observed marked alterations in expression patterns in the surrounding cumulus cells, that include a massive deregulation of transcripts related to fatty acid synthesis, accumulation, elongation and desaturation, $\beta$-oxidation and glycolysis (del Collado et al., 2017a). These data suggest that IVM drastically interferes with the cumulus cells transcription, while modifications in lipid quantity occurs in both cumulus cells and oocyte. Considering the intense communication within COC, we could suggest that these alterations could modify the synthesis of fatty acids into cumulus cells and the quantity of molecules trafficking between soma and germ cells. This principle was given proof by the investigation of lipid traffic from cumulus cells to oocytes via a lipid-carrying protein (FABP3) and TZPs (del Collado et al., 2017b). We identified FABP3 within TZPs in bovine immature and in vitro mature oocytes. Moreover, we demonstrated that FABP3 protein and lipids increased in in vitro matured cumulus cells and oocytes, but not in in vivo counterparts, suggesting that in in vitro conditions the increase of lipid synthesis and accumulation in cumulus cells is, at least partially, transferred to the oocytes via TZPs.

The glucose metabolism is also affected by IVM. COCs undergoing IVM produce higher levels of lactate (Khurana and Niemann, 2000) and cumulus cells after IVM have higher expression of glycolysis related genes when compared to in vivo maturation (del Collado et al., 2017a). If in vitro maturated cumulus cells metabolized more glucose and produced higher lactate, it could be implied that these cells provide to the oocyte higher level metabolites from glycolysis by gap junctions. Herein, we expose evidence suggesting that IVM affect COC communication by several different ways, being able to influence the oocyte competence and embryo development. We pointed out some mechanisms and pathways affected by in vitro maturation and their implications in oocyte competence. However, some important questions remain: can we modulate COC communication during IVM? Is this strategy viable to increase oocyte quality?

Increase communication time between cumulus cells and the oocyte is a strategy under investigation in recent years by the use of pre-maturation systems before IVM. The pre-maturation are proposed to maintain TZPs and gap junctions functional for longer periods during in vitro culture. This is achieved with the use of substances that modulate cAMP and the meiotic resumption (Gilchrist and Thompson, 2007). Studies have demonstrated that pre-maturation systems increase oocyte quality and blastocysts rates during IVP in several mammals (Thomas et al., 2004b; Gilchrist and Thompson, 2007; Li et al., 2016; Sugimura et al., 2018). At a glance, the strategy to improve oocyte quality by increasing cumulus cells-oocyte communication during IVM could provide to the oocyte similar amounts of molecules, such as mRNA and metabolites, as in vivo maturated oocytes. However, one thing that has to be taken into account is that, during IVM, oocytes' population is very heterogeneous containing oocytes at different GV stages. These differential GVs stages could be differently affected by the pre-maturation systems. Oocytes in GV1 could benefit from this system, accumulating more molecules from cumulus cells, whereas more advance GV3 oocytes, with fewer gap junctions, could be adversely affected by in vitro maturation without any advantage by pre-maturation. Moreover, we have to consider that, as previously described, in vitro maturated cumulus cells are negatively affect by in vitro culture, so the quantity and type of molecules transiting from cumulus to the oocyte could be non-physiological and not beneficial as expected.

On the other hand, a different strategy to modify COC communication is the supplementation with EVs during IVM. There are studies demonstrating a positive influence of supplementation with extracellular vesicles during IVM in cumulus cells expansion, blastocyst rate, blastocysts cryotolerance and gene expression in the COCs (Hung et al., 2015; Lopera-Vasquez et al., 2016). Furthermore, supplementation with EVs from follicular fluid of 3-6 $\mathrm{mm}$ follicles during IVM and IVC altered the expression of metabolic and developmental related genes, miRNA profile and epigenetic marks in blastocyst (da Silveira et al., 2017). These studies suggest that EVs play roles during oocyte maturation and embryo development. However, to develop such 
strategy, is important to understand the role of these extracellular vesicles within the ovarian follicle as well as the specific roles of their contents in order to supplement the right 'messages' to cumulus-oocytescomplexes during maturation.

\section{Acknowledgments}

The authors would like to thank the Sao Paulo Research Foundation (FAPESP grants 2018/01431-9, 2017/19825-0, 2014/21034-3; 2014/22887-0; and 2013/08135-2)

\section{References}

Andrade G, Meirelles F, Perecin F, da Silveira JC. 2017a. Cellular and extracellular vesicular origins of miRNAs within the bovine ovarian follicle. Reprod Domest Anim, 52:1036-1045.

Andrade GM, da Silveira JC, Perrini C, Del Collado M, Gebremedhn S, Tesfaye D, Meirelles FV, Perecin F. 2017 b. The role of the PI3K-Akt signaling pathway in the developmental competence of bovine oocytes. PLoS One, 12:e185045. doi: 10.1371/journal.pone. 0185045 .

Assou S, Al-edani T, Haouzi D, Philippe N, Lecellier CH, Piquemal D, Commes T, Ait-Ahmed O, Dechaud H, Hamamah S. 2013. MicroRNAs: new candidates for the regulation of the human cumulusoocyte complex. Hum Reprod, 28:3038-3049.

Bergandi L, Basso G, Evangelista F, Canosa S, Dalmasso P, Aldieri E, Revelli A, Benedetto C. Ghigo D. 2014. Inducible Nitric Oxide Synthase and Heme Oxygenase 1 Are Expressed in Human Cumulus Cells and May Be Used as Biomarkers of Oocyte Competence. Reprod Sci, 21:1370-1377.

Biggers JD, Whittingham DG, Donahue RP. 1967. The pattern of energy metabolism in the mouse oocyte and zygote. Proc Natl Acad Sci US A, 58:560-567.

Carabatsos MJ, Elvin J, Matzuk MM, Albertini DF. 1998. Characterization of oocyte and follicle development in growth differentiation factor-9-deficient mice. Dev Biol, 204:373-384.

Chang HM, Cheng JC, Taylor E, Leung PC. 2014 Oocyte-derived BMP15 but not GDF9 down-regulates connexin43 expression and decreases gap junction intercellular communication activity in immortalized human granulosa cells. Mol Hum Reprod, 20:373-383.

Chang HM, Qiao J, Leung PC. 2016. Oocyte-somatic cell interactions in the human ovary-novel role of bone morphogenetic proteins and growth differentiation factors. Hum Reprod Update, 23:1-18.

Choi DS, Kim DK, Kim YK, Gho YS. 2013 Proteomics, transcriptomics and lipidomics of exosomes and ectosomes. Proteomics, 13:1554-1571.

Cillo F, Brevini TAL, Antonini S, Paffoni A, Ragni G, Gandolfi F. 2007. Association between human oocyte developmental competence and expression levels of some cumulus genes. Reproduction, 134:645-650.

Clarke H. 2017. Control of Mammalian Oocyte Development by Interactions with the Maternal Follicular Environment. Results Probl Cell Differ,
63:17-41.

Clarke HJ. 2018. Regulation of germ cell development by intercellular signaling in the mammalian ovarian follicle. Wiley Interdiscip Rev Dev Biol, 7. doi: 10.1002/wdev.294.

Combelles CMH, Carabatsos MJ, Kumar TR, Matzuk MM, Albertini DF. 2004. Hormonal control of somatic cell oocyte interactions during ovarian follicle development. Mol Reprod Dev, 69:347-355.

Conti M, Hsieh M, Zamah AM, Oh JS. 2012. Novel signaling mechanisms in the ovary during oocyte maturation and ovulation. Mol Cell Endocrinol, 356:6573.

da Silveira JC, Veeramachaneni DN, Winger QA, Carnevale EM, Bouma GJ. 2012. Cell-secreted vesicles in equine ovarian follicular fluid contain miRNAs and proteins: a possible new form of cell communication within the ovarian follicle. Biol Reprod, $86: 71$.

da Silveira JC, de Andrade GM, Nogueira MFG, Meirelles FV, Perecin F. 2015. Involvement of miRNAs and Cell-Secreted Vesicles in Mammalian Ovarian Antral Follicle Development. Reprod Sci, 22:1474-1483.

da Silveira JC, Andrade GM, Del Collado M, Sampaio RV, Sangalli JR, Silva LA, Pinaffi FVL, Jardim IB, Cesar MC, Nogueira MFG, Cesar ASM, Coutinho LL, Pereira RW, Perecin F, Meirelles FV. 2017. Supplementation with small-extracellular vesicles from ovarian follicular fluid during in vitro production modulates bovine embryo development. PloS one, 12:e179451.

de Loos F, van Vliet C, van Maurik P, Kruip TA. 1989. Morphology of immature bovine oocytes. Gamete Res, 24:197-204.

de Loos F, Kastrop P, Van Maurik P, Van Beneden TH, Kruip TA. 1991. Heterologous cell contacts and metabolic coupling in bovine cumulus oocyte complexes. Mol Reprod Dev, 28:255-259.

del Collado M, Saraiva NZ, Lopes FL, Gaspar RC, Padilha LC, Costa RR, Rossi GF, Vantini R, Garcia JM. 2016. Influence of bovine serum albumin and fetal bovine serum supplementation during in vitro maturation on lipid and mitochondrial behaviour in oocytes and lipid accumulation in bovine embryos. Reprod Fertil Dev, 28:1721. doi: 10.1071/RD15067.

del Collado M, da Silveira JC, Oliveira MLF, Alves BMSM, Simas CS, Godoy AT, Coelho MB, Marques LA, Carriero MM, Nogueira MFG, Eberlin MN, Silva LA, Meirelles FV, Perecin F. 2017a. In vitro maturation impacts cumulus oocyte complex metabolism and stress in cattle. Reproduction, 154:881893.

del Collado M, da Silveira JC, Sangalli JR, Andrade GM, Sousa L, Silva LA, Meirelles FV, Perecin F. 2017b. Fatty Acid Binding Protein 3 And Transzonal Projections Are Involved In Lipid Accumulation During In vitro Maturation Of Bovine Oocytes. Sci Rep, 7:2645.

Di Pietro C. 2016. Exosome-mediated communication in the ovarian follicle. J Assist Reprod Genet, 33:303311 . 
Dong JW, Albertini DF, Nishimori K, Kumar TR, Lu NF, Matzuk MM. 1996. Growth differentiation factor-9 is required during early ovarian folliculogenesis. Nature, 383:531-535.

Edson MA, Nagaraja AK, Matzuk MM. 2009. The mammalian ovary from genesis to revelation. Endocr Rev, 30:624-712.

El-Hayek S, Yang Q, Abbassi L, FitzHarris G, Clarke HJ. 2018. Mammalian Oocytes Locally Remodel Follicular Architecture to Provide the Foundation for Germline-Soma Communication. Curr Biol, 28:1124-1131e3.

Eppig JJ. 2001. Oocyte control of ovarian follicular development and function in mammals. Reproduction, 122:829-838

Eppig JJ, Pendola FL, Wigglesworth K, Pendola JK. 2005. Mouse oocytes regulate metabolic cooperativity between granulosa cells and oocytes: Amino acid transport. Biol Reprod, 73:351-357.

Fair T, Hyttel P, Greve T. 1995. Bovine oocyte diameter in relation to maturational competence and transcriptional activity. Mol Reprod Dev, 42:437-442.

Feuerstein P, Puard V, Chevalier C, Teusan R, Cadoret V, Guerif F, Houlgatte R, Royere D. 2012. Genomic Assessment of Human Cumulus Cell Marker Genes as Predictors of Oocyte Developmental Competence: Impact of Various Experimental Factors. Plos One, 7:e40449.

FitzHarris G, Siyanov V, Baltz JM. 2007. Granulosa cells regulate oocyte intracellular $\mathrm{pH}$ against acidosis in preantral follicles by multiple mechanisms. Development, 134:4283-4295.

Fortune JE. 1994. Ovarian follicular growth and development in mammals. Biol Reprod, 50:225-232.

Fukui Y, Sakuma Y. 1980. Maturation of bovine oocytes cultured in vitro: relation to ovarian activity, follicular size and the presence or absence of cumulus cells. Biol Reprod, 22:669-673.

Gershon E, Plaks V, Dekel N. 2008. Gap junctions in the ovary: expression, localization and function. $\mathrm{Mol}$ Cell Endocrinol, 282:18-25.

Gilchrist RB, Thompson JG. 2007. Oocyte maturation: emerging concepts and technologies to improve developmental potential in vitro. Theriogenology, 67:6-15.

Gilchrist RB, Lane M, Thompson JG. 2008. Oocytesecreted factors: regulators of cumulus cell function and oocyte quality. Hum Reprod Update, 14:59-177.

Granot I, Dekel N. 2002. The ovarian gap junction protein connexin43: regulation by gonadotropins. Trends Endocrin Met, 13:310-313.

Heinzmann J, Hansmann T, Herrmann D, Wrenzycki C, Zechner U, Haaf T, Niemann H. 2011. Epigenetic profile of developmentally important genes in bovine oocytes. Mol Reprod Dev, 78:188-201.

Hung WT, Hong XA, Christenson LK, McGinnis LK. 2015. Extracellular Vesicles from Bovine Follicular Fluid Support Cumulus Expansion. Biol Reprod, 93. doi: 10.1095/biolreprod.115.132977.

Jaffe LA, Egbert JR. 2017. Regulation of Mammalian Oocyte Meiosis by Intercellular Communication Within the Ovarian Follicle. Annu Rev Physiol, 79:237-260.
Jiang Z, Sun J, Dong H, Luo O, Zheng X, Obergfell C, Tang Y, Bi J, O'Neill R, Ruan Y, Chen J, Tian XC. 2014. Transcriptional profiles of bovine in vivo pre-implantation development. BMC Genomics, 15:756. doi: 10.1186/1471-2164-15-756.

Jones GM, Cram DS, Song B, Magli MC, Gianaroli L, Lacham-Kaplan O, Findlay JK, Jenkin G, Trounson AO. 2008. Gene expression profiling of human oocytes following in vivo or in vitro maturation. Hum Reprod, 23:1138-1144.

Kaivo-Oja N, Bondestam J, Kamarainen $M$, Koskimies J, Vitt U, Cranfield M, Vuojolainen K, Kallio JP, Olkkonen VM, Hayashi M, Moustakas A, Groome NP, ten Dijke P, Hsueh AJW, Ritvos O. 2003. Growth differentiation factor-9 induces $\operatorname{Smad} 2$ activation and inhibin B production in cultured human granulosa-luteal cells. J Clin Endocr Metab, 88:755762.

Kaivo-Oja N, Mottershead DG, Mazerbourg S, Myllymaa S, Duprat S, Gilchrist RB, Groome NP, Hsueh AJ, Ritvos O. 2005. Adenoviral gene transfer allows Smad-responsive gene promoter analyses and delineation of type I receptor usage of transforming growth factor-beta family ligands in cultured human granulosa luteal cells. J Clin Endocr Metab, 90:271278.

Katz-Jaffe MG, McCallie BR, Preis KA, Filipovits J, Gardner DK. 2009. Transcriptome analysis of in vivo and in vitro matured bovine MII oocytes. Theriogenology, 71:939-946.

Khurana NK, Niemann H. 2000. Energy metabolism in preimplantation bovine embryos derived in vitro or in vivo. Biol Reprod, 62:847-856.

Kues WA, Sudheer S, Herrmann D, Carnwath JW, Havlicek V, Besenfelder U, Lehrach H, Adjaye J, Niemann H. 2008. Genome-wide expression profiling reveals distinct clusters of transcriptional regulation during bovine preimplantation development in vivo. Proc Natl Acad Sci US A, 105:19768-19773.

Li HJ, Sutton-McDowall ML, Wang X, Sugimura S, Thompson JG, Gilchrist RB. 2016. Extending prematuration with cAMP modulators enhances the cumulus contribution to oocyte antioxidant defence and oocyte quality via gap junctions. Hum Reprod, 31:810821.

Li R, Albertini DF. 2013. The road to maturation: somatic cell interaction and self-organization of the mammalian oocyte. Nat Rev Mol Cell Biol, 14:141-152.

Lodde V, Franciosi F, Tessaro I, Modina SC, Luciano AM. 2013. Role of gap junction-mediated communications in regulating large-scale chromatin configuration remodeling and embryonic developmental competence acquisition in fully grown bovine oocyte. $J$ Assist Reprod Genet, 30:1219-1226.

Lodde V, Modina S, Galbusera C, Franciosi F, Luciano AM. 2007. Large-scale chromatin remodeling in germinal vesicle bovine oocytes: Interplay with gap junction functionality and developmental competence. Mol Reprod Dev, 74:740-749.

Lodde V, Modina S, Maddox-Hyttel P, Franciosi F, Lauria A, Luciano AM. 2008. Oocyte morphology and transcriptional silencing in relation to chromatin 
remodeling during the final phases of bovine oocyte growth. Mol Reprod Dev, 75:915-924.

Lonergan P, Monaghan P, Rizos D, Boland MP, Gordon I. 1994. Effect of Follicle Size on Bovine Oocyte Quality and Developmental Competence Following Maturation, Fertilization, and Culture inVitro. Mol Reprod Dev, 37:48-53.

Lopera-Vasquez R, Hamdi M, Fernandez-Fuertes B, Maillo V, Beltran-Brena P, Calle A, Redruello A, Lopez-Martin S, Gutierrez-Adan A, Yanez-Mo M, Ramirez MA, Rizos D. 2016. Extracellular Vesicles from BOEC in In vitro Embryo Development and Quality. PloS one, 11: e0148083. doi: 10.1371/journal.pone.0148083.

Luciano AM, Lodde V, Beretta MS, Colleoni S, Lauria A, Modina S. 2005. Developmental capability of denuded bovine oocyte in a co-culture system with intact cumulus-oocyte complexes: role of cumulus cells, cyclic adenosine 3',5'-monophosphate, and glutathione. Mol Reprod Dev, 71:389-397.

Luciano AM, Franciosi F, Modina SC, Lodde V. 2011. Gap junction-mediated communications regulate chromatin remodeling during bovine oocyte growth and differentiation through cAMP-dependent mechanism(s). Biol Reprod, 85:1252-1259.

Luciano AM, Sirard MA. 2018. Successful in vitro maturation of oocytes: a matter of follicular differentiation. Biol Reprod, 98:162-169.

Macaulay AD, Gilbert I, Caballero J, Barreto R, Fournier E, Tossou P, Sirard MA, Clarke HJ, Khandjian EW, Richard FJ, Hyttel P, Robert C. 2014. The gametic synapse: RNA transfer to the bovine oocyte. Biol Reprod, 91:90. doi:10.1095/biolreprod.114.119867

Macaulay AD, Gilbert I, Scantland S, Fournier E, Ashkar F, Bastien A, Saadi HA, Gagne D, Sirard MA, Khandjian EW, Richard FJ, Hyttel P, Robert C. 2016. Cumulus Cell Transcripts Transit to the Bovine Oocyte in Preparation for Maturation. Biol Reprod, 94:16. doi:10.1095/biolreprod.114.127571.

Matoba S, Bender K, Fahey AG, Mamo S, Brennan L, Lonergan P, Fair T. 2014. Predictive value of bovine follicular components as markers of oocyte developmental potential. Reprod Fertil Dev, 26:337345 .

McBride D, Carre W, Sontakke SD, Hogg CO, Law A, Donadeu FX, Clinton M. 2012. Identification of miRNAs associated with the follicular-luteal transition in the ruminant ovary. Reproduction, 144:221-233.

Moore RK, Otsuka F, Shimasaki S. 2003. Molecular basis of bone morphogenetic protein-15 signaling in granulosa cells. J Biol Chem, 278:304-310.

Navakanitworakul $R$, Hung WT, Gunewardena $S$, Davis JS, Chotigeat W, Christenson LK. 2016. Characterization and Small RNA Content of Extracellular Vesicles in Follicular Fluid of Developing Bovine Antral Follicles. Sci Rep, 6:25486. doi: 10.1038/srep25486.

Norris RP, Ratzan WJ, Freudzon M, Mehlmann LM, Krall J, Movsesian MA, Wang HC, Ke HM, Nikolaev VO, Jaffe LA. 2009. Cyclic GMP from the surrounding somatic cells regulates cyclic AMP and meiosis in the mouse oocyte. Development, 136:18691878.

Nuttinck F, Peynot N, Humblot P, Massip A, Dessy F, Flechon JE. 2000. Comparative immunohistochemical distribution of connexin 37 and connexin 43 throughout folliculogenesis in the bovine ovary. Mol Reprod Dev, 57:60-66.

Petrocelli T, Lye SJ. 1993. Regulation of transcripts encoding the myometrial gap junction protein, connexin-43, by estrogen and progesterone. Endocrinology, 133:284-290.

Pulkki MM, Myllymaaa S, Pasternack A, Lun S, Ludlow H, Al-Qahtani A, Korchynskyi O, Groome N, Juengel JL, Kalkkinen N, Laitinen M, Ritovs O, Mottershead DG. 2011. The bioactivity of human bone morphogenetic protein-15 is sensitive to C-terminal modification: Characterization of the purified untagged processed mature region. Mol Cell Endocrinol, 332:106-115.

Raposo G, Stoorvogel W. 2013. Extracellular vesicles: Exosomes, microvesicles, and friends. $J$ Cell Biol, 200:373-383

Rizos D, Fair T, Papadopoulos S, Boland MP, Lonergan P. 2002a. Developmental, qualitative, and ultrastructural differences between ovine and bovine embryos produced in vivo or in vitro. Mol Reprod Dev, 62:320-327.

Rizos D, Ward F, Duffy P, Boland MP, Lonergan P. 2002b. Consequences of bovine oocyte maturation, fertilization or early embryo development in vitro versus in vivo: Implications for blastocyst yield and blastocyst quality. Mol Reprod Dev, 61:234-248.

Robert C, Gilbert I. 2018. Cell-to-Cell Communication in the Ovarian Follicle. In book: Module in Biomedical Sciences. Elsevier, doi:10.1016/B978-0-12-801238-3.64391-X.

Russell DL, Gilchrist RB, Brown HM, Thompson JG. 2016. Bidirectional communication between cumulus cells and the oocyte: Old hands and new players? Theriogenology, 86:62-68.

Sang Q, Yao ZY, Wang H, Feng RZ, Wang HJ, Zhao XZ, Xing QH, Jin L, He L, Wu LQ, Wang L. 2013. Identification of MicroRNAs in Human Follicular Fluid: Characterization of MicroRNAs That Govern Steroidogenesis in vitro and Are Associated With Polycystic Ovary Syndrome in vivo. J Clin Endocrinol Metab, 98:3068-3079.

Santonocito M, Vento M, Guglielmino MR, Battaglia R, Wahlgren J, Ragusa M, Barbagallo D, Borzi P, Rizzari S, Maugeri M, Scollo P, Tatone C, Valadi H, Purrello M, Di Pietro C. 2014. Molecular characterization of exosomes and their microRNA cargo in human follicular fluid: bioinformatic analysis reveals that exosomal microRNAs control pathways involved in follicular maturation. Fertil Steril, 102:1751-U1590.

Seidel GE. 2006. Modifying oocytes and embryos to improve their cryopreservation. Theriogenology, 65:228-235.

Sinha PB, Tesfaye D, Rings F, Hossien M, Hoelker M, Held E, Neuhoff C, Tholen E, Schellander K, Salilew-Wondim D. 2017. MicroRNA-130b is involved in bovine granulosa and cumulus cells function, oocyte 
maturation and blastocyst formation. $J$ Ovarian Res, 10:37. doi: 10.1186/s13048-017-0336-1.

Sirard MA, Richard F, Mayes M. 1998. Controlling meiotic resumption in bovine oocytes: A review. Theriogenology, 49:483-497.

Sohel MMH, Hoelker M, Noferesti SS, SalilewWondim D, Tholen E, Looft C, Rings F, Uddin MJ, Spencer TE, Schellander K, Tesfaye D. 2013. Exosomal and Non-Exosomal Transport of ExtraCellular microRNAs in Follicular Fluid: Implications for Bovine Oocyte Developmental Competence. PLoS One, 8:e78505. doi: 10.1371/journal.pone.0078505.

Sugimura S, Yamanouchi T, Palmerini MG, Hashiyada Y, Imai K, Gilchrist RB. 2018. Effect of pre-in vitro maturation with cAMP modulators on the acquisition of oocyte developmental competence in cattle. J Reprod Dev, 64:233-241.

Sugiura K, Eppig JJ. 2005. Society for Reproductive Biology Founders' Lecture 2005 - Control of metabolic cooperativity between oocytes and their companion granulosa cells by mouse oocytes. Reprod Fert Dev, 17:667-674.

Sutton ML, Cetica PD, Beconi MT, Kind KL, Gilchrist RB, Thompson JG. 2003a. Influence of oocyte-secreted factors and culture duration on the metabolic activity of bovine cumulus cell complexes. Reproduction, 126:27-34.

Sutton ML, Gilchrist RB, Thompson JG. 2003b. Effects of in-vivo and in-vitro environments on the metabolism of the cumulus-oocyte complex and its influence on oocyte developmental capacity. Hum Reprod Update, 9:35-48.
Sutton-McDowall ML, Gilchrist RB, Thompson JG. 2010. The pivotal role of glucose metabolism in determining oocyte developmental competence. Reproduction, 139:685-695.

Thomas RE, Armstrong DT, Gilchrist RB. 2004a. Bovine cumulus cell-oocyte gap junctional communication during in vitro maturation in response to manipulation of cell-specific cyclic adenosine 3',5'monophosophate levels. Biol Reprod, 70:548-556.

Thomas RE, Thompson JG, Armstrong DT, Gilchrist RB. 2004b. Effect of specific phosphodiesterase isoenzyme inhibitors during in vitro maturation of bovine oocytes on meiotic and developmental capacity. Biol Reprod, 71:1142-1149.

Vaccari S, Weeks JL, Hsieh M, Menniti FS, Conti M. 2009. Cyclic GMP Signaling Is Involved in the Luteinizing Hormone-Dependent Meiotic Maturation of Mouse Oocytes. Biol Reprod, 81:595-604.

Yan C, Wang P, DeMayo J, DeMayo FJ, Elvin JA, Carino C, Prasad SV, Skinner SS, Dunbar BS, Dube JL, Celeste AJ, Matzuk MM. 2001. Synergistic roles of bone morphogenetic protein 15 and growth differentiation factor 9 in ovarian function. Mol Endocrinol, 15:854-866.

Yuan Y, Ida JM, Paczkowski M, Krisher RL. 2011. Identification of Developmental Competence-Related Genes in Mature Porcine Oocytes. Mol Reprod Dev, 78:565-575.

Zhang L, Jiang S, Wozniak PJ, Yang X, Godke RA. 1995. Cumulus cell function during bovine oocyte maturation, fertilization, and embryo development in vitro. Mol Reprod Dev, 40:338-344. 